\title{
REFORMA PREVIDENCIÁRIA E SINDICALISMO: experiências internacionais e lições nacionais
}

\section{PENSION SYSTEM REFORM AND TRADE UNION RESISTANCE: international experiences and nationals lessons}

\author{
Sidartha Soria* \\ Darcilene Claudio Gomes ${ }^{\star *}$
}

\begin{abstract}
Resumo
O artigo tem como objetivo apresentar casos de reforma previdenciária efetuados em alguns países e as posturas assumidas pelo movimento sindical, discutindo de que modo a relação entre reforma e sindicalismo se apresenta no Brasil. O último quartil do século XX viu a ressurreição do ideário liberalizante na condução de processos de reforma institucionais e legais. Em seu caminho, estavam diferentes sistemas estatais de seguridade social. Neste sentido, a ocorrência de reformas previdenciárias é parte do movimento geral de crítica neoliberal do Estado de Bem-Estar Social. Esta mesma conjuntura adversa atinge a classe trabalhadora, na forma de crises econômicas que elevam os níveis de desemprego e de precarização do trabalho, correndo assim as bases sobre as quais se estruturam os sindicatos, que entram em um período de crise. Assim, serão analisadas as experiências de reforma na Suécia, França e Estados Unidos, e, por fim, o caso brasileiro. Conclui-se que a participação do movimento sindical, bem como os valores e referências componentes de seu ideário político-ideológico, são fatores influentes no tocante ao encaminhamento de processos de reforma.
\end{abstract}

Palavras-chave: Sindicalismo. Trabalho. Sistema previdenciário. Reforma

\begin{abstract}
This paper aims to raise some international cases of pension reform occurred, as well as trade union stances on the issue, and also to discuss in which way this relation between trade unionism and pension reform is set in Brazil. The last decades of $20^{\text {th }}$ century testified a resurrection of a hegemonic liberal perspective guiding the processes of institutional and legal reforms. In its path there were a number of State-sponsored Social Security systems. Pension reforms, in this regard, are part of general movement of liberal criticism of Welfare State. This same situation reaches the working class by generation of economic crisis that causes the increase of unemployment rates and labor precariousness, which undermines Trade unions' strength. We analyze the reform experiences occurred in Sweden, France and United States, and then to Brazilian context. It concludes that unionism participation, as much as its political and cultural values are influent factors concerning to accomplishment of reform processes.
\end{abstract}

Keywords: Trade Union. Labor. Pension System. Reform

\section{Introdução}

Este artigo tem como objetivo levantar, no plano internacional, alguns casos de tentativa de reforma de sistemas previdenciários público-estatais e as posturas assumidas pelo movimento sindical. As últimas décadas do século XX viram a ressurreição do ideário liberalizante como

\footnotetext{
* Doutor em Sociologia pela Universidade Estadual de Campinas e professor adjunto da Universidade Federal de Pernambuco. E-mail: sidartha.soria@gmail.com

** Doutora em Economia Aplicada pela Universidade Estadual de Campinas e pesquisadora da Fundação Joaquim Nabuco. E-mail: darcilene.gomes@gmail.com
} 
hegemônico na condução de processos de reforma institucionais e legais. Em seu caminho, estavam diferentes sistemas estatais de seguridade social.

Neste sentido, a ocorrência de reformas previdenciárias é parte do movimento geral de crítica (neo) liberal do Estado de Bem-Estar Social. Esta mesma conjuntura adversa atinge a classe trabalhadora, na forma de crises econômicas que elevam os níveis de desemprego e de precarização do trabalho, correndo assim as bases sobre as quais se estruturam os sindicatos que, desta forma, entram em um longo período de crise.

Conforme lembra Antunes (1995), diversos países industrializados, que então contavam com movimentos sindicais fortes, enfrentam uma tendência de dessindicalização. No contexto geral da crise do sindicalismo ocorrem tendências tais como a da individualização crescente das relações de trabalho, da desregulamentação e flexibilização do mercado de trabalho, do recuo geral do sindicalismo para a posição da "participação" ou legitimação de aspectos da nova ordem hostis aos trabalhadores etc. Enfraquecido em suas bases e relativamente desorientado em função do avanço liberalizante e da consolidação do capitalismo liderado pela finança, os sindicatos devem encarar o cerco montado contra os direitos sociais e trabalhistas - e, no que interessa especificamente a este trabalho, às conquistas cristalizadas nos sistemas de previdência público-estatal, um ambiente que contou, de modos e graus diversos, com a participação do movimento sindical, e do qual não raro ele participa, direta ou indiretamente.

Daí a necessidade de se fazer um levantamento das experiências de reformulação almejada ou concretizada - de instituições estatais previdenciárias, componentes dos sistemas públicos de bem-estar social em diversas sociedades, bem como se situou o movimento sindical em relação a tais experiências.

Nestes termos, o artigo é composto por três partes, além desta introdução e da conclusão. Na primeira, faz-se um breve levantamento das reflexões em torno da importância do movimento sindical na constituição de sistemas públicos de bem-estar social. A segunda parte traz as experiências de reforma previdenciária ocorridas em três países - os quais seriam representativos de boa parte das modalidades de seguridade social existentes -, bem como, no início, algumas justificativas dos propositores de reformas liberalizantes. Por fim, o terceiro item procura tecer breves considerações em relação à questão na especificidade brasileira.

\section{A importância do sindicalismo na (des) construção da seguridade social}

Em que pese a importância das descobertas do marxismo estruturalista a partir da proposição teórica segundo a qual existem relações necessárias (ou estruturais) entre Estado de Bem-Estar Social e a dinâmica da acumulação capitalista (O'CONNOR, 1977; GOUGH, 1979), parte-se da premissa de que os sistemas públicos de seguridade social se constituem (e também se retraem) em função da dinâmica das classes sociais como agentes de mudança, no sentido da desmercadorização (ESPING-ANDERSEN, 1990). 
Assim, na escalada histórica dos direitos sob o capitalismo, o desejo pela diminuição das agudas assimetrias socioeconômicas entre as classes conduziu os assalariados a se organizarem politicamente, tanto em âmbito político-institucional - levando à conquista de direitos políticos - como no âmbito econômico-produtivo - em que o sindicalismo, através da obtenção do direito à negociação coletiva, logrou criar um "sistema secundário de cidadania industrial paralelo" (MARSHALL, 1967, p. 86).

Para tanto, as classes assalariadas organizaram-se sob ideários político-ideológicos não apenas tipicamente socialistas, mas também social-cristãos (católicos, protestantes), étniconacionais, pré-capitalistas etc. (ESPING-ANDERSEN, 1990). Também não se restringiram à atuação político-parlamentar, mas também abrangendo mecanismos neocorporatistas de mediação de interesses (SCHMITTER, 1974). E, em sua luta política, se abriram a composições ou coalizões de natureza interclasse, como setores da classe proprietária e das classes médias (PRZEWORSKI, 1985; GOUREVITCH, 1986), os quais também se viam beneficiados, de modos diversos, pelos sistemas públicos de seguridade social (MARES, 2000).

Deste modo, por surgirem em função da melhoria das condições de vida e de trabalho da classe assalariada, parece restar poucas dúvidas de que o movimento sindical foi o fator fundamental para a emergência dos diversos tipos de sistemas públicos de seguridade social, impulsionando decididamente a luta pela saúde e segurança ocupacionais, lutas salariais e por direitos diversos no âmbito laboral (DONADO; WÄLDE, 2012), bem como tomando parte, em diversos países industrializados, na estruturação e gestão de aparelhos público-estatais de seguridade social (STREECK; HASSEL, 2003).

Naturalmente, a questão previdenciária está entre os elementos centrais da pauta sindical. Para alguns autores (BRUGIAVINI et al., 2001), os sindicatos têm, em tese, interesse em incentivar ou promover a instituição de sistemas previdenciários os mais generosos possíveis. Quanto maior a cobertura obrigatória (bem como a participação público-estatal no sistema), maior a mitigação de riscos de insolvência, maior o potencial redistributivo de renda e maior será o bem-estar geral. Por outro lado, sistemas voluntários de previdência podem levar contribuintes a deixarem o sistema por se negarem a subsidiar os benefícios de outros. Haveria a possibilidade de o sindicato advogar benefícios para seus próprios trabalhadores membros ou filiados, mas também não seria a melhor situação, pois uma base de contribuintes obviamente mais estreita e dependente da taxa de sindicalização e do nível de (des) emprego representariam fatores crônicos de instabilidade para tal sistema (BRUGIAVINI et al., 2001).

Refletindo diferentes tradições políticas e legados institucionais, os papeis dos sindicatos na política de bem-estar social - e, particularmente, previdenciária - variam de país a país. Partindo de uma combinação de caracterizações e tipologias de welfare feitas por autores diversos, Natali e Rhodes (2003) propõem, para a Europa, quatro tipos gerais de sistema previdenciário: 1) sistemas puramente ocupacionais; 2 ) sistemas ocupacionais e focalizados (com teste de meios); 3) sistemas universais e ocupacionais; e 4) sistemas puramente universais. 
O grupo composto pelos tipos 1 (que teria, como representantes, países como Alemanha e Áustria) e 2 (França, Itália, Espanha) tem inspiração bismarckiana - ou seja, são baseados na modalidade de seguro social, vinculado ao trabalho e ao salário, financiados principalmente por contribuições proporcionais de trabalhadores e empregadores, enquanto o grupo do qual fazem parte os tipos 3 (Holanda, Reino Unido) e 4 (Suécia) aproximar-se-iam do modelo beveridgeano - baseiam-se na concepção de inclusão do conjunto da população, financiados pelo tesouro público e com o objetivo de prover um sustento básico, no âmbito da subsistência (NATALI; RHODES, 2003).

É interessante observar que Bismarck havia elaborado o sistema de seguro social para bloquear a influência dos sindicatos na gestão direta da questão previdenciária, mas que, com o tempo, cedeu lugar a uma lógica em que os sindicatos ocupariam lugar de destaque na negociação e condução mais direta dos arranjos no sistema de seguro social. Por outro lado, Beveridge, no contexto da II Guerra Mundial, pensou num sistema de benefícios que assegurasse os mínimos sociais a toda a população, então assolada pelo conflito mundial - o que, anos depois, levaria tanto ao surgimento de sistemas de tipo universal-ocupacional (universal nos "mínimos sociais", ocupacional para a classe assalariada), que é o tipo 3, quanto ao surgimento de sistemas de seguridade plena, de benefícios mais amplos e universais, caso do tipo 4. Finalmente, tais tipos se referem a realidades dinâmicas, que foram objeto de mudanças diversas ao longo de sua história - como é o exemplo do caso britânico, em que a lógica baseada na máxima do primeiro-ministro britânico Clement Attle, de um sistema público que protegesse o cidadão "do berço ao túmulo", foi sendo lentamente deslocada em direção à lógica do sistema de benefícios gerais mínimos e complementaridade de benefícios por fundos de pensão, com o sindicalismo pressionando indiretamente, politicamente, o Estado a implementar tais sistemas de seguridade (SORIA, 2011).

Finalmente, deve-se considerar também, nesta questão das relações entre sindicalismo e previdência, os achados analíticos derivados do estudo empírico deste ponto em diversos casos europeus nacionais, feitos por Brugiavini et al. (2001). Segundo estes autores, os sindicatos buscaram promover a expansão de sistemas previdenciários, como dito, tanto para melhorar as condições de vida gerais da população assalariada, quanto para ampliarem seu poder de negociação coletiva. Contudo, com uma pauta de reivindicações mais ampla, ocorre a tendência à polarização entre interesses de trabalhadores mais jovens e trabalhadores mais velhos, incluídos aí os aposentados.

Ou seja, estão discutindo o que chamam de "viés da senioridade": tendo à sua disposição mais tempo e recursos para se dedicarem ao meio sindical, os trabalhadores mais velhos começam a priorizar os interesses próprios de sua condição. Enquanto os trabalhadores e dirigentes sindicais mais jovens estariam preocupados com temas como o nível de emprego, as condições de trabalho e o constante risco de layoffs, os trabalhadores e sindicalistas mais velhos estariam mais focados em temas como o valor e a extensão de seus benefícios previdenciários 
e o valor líquido dos salários, especialmente quando o valor dos primeiros está atrelado aos segundos. Tal fenômeno de polarização pode ocasionar ou intensificar tanto o envelhecimento dos membros do sindicato (gerontocracia), quanto ir afastando os trabalhadores mais jovens dos sindicatos (BRUGIAVINI et al., 2001).

Dada, portanto, a importância central do sindicalismo na construção dos modernos welfare states - inicialmente na forma de associações de ajuda mútua; depois, formando partidos ou aliançando-se a estes pela expansão de direitos sociais; e, finalmente, chegando a possuir papeis institucionalizados na gestão pública do bem-estar social -, certamente seu papel em contextos de crise econômica ou sistêmica também não será desprezível. É o que se verá a seguir.

\section{Experiências internacionais de reforma previdenciária e o papel sindical}

\section{O retorno do liberalismo}

Com a crise do "capitalismo regulado" nos anos de 1970, abre-se caminho para o recrudescimento da crítica liberal a ingerências "extraeconômicas" sobre a esfera do mercado, bem como àqueles que seriam os grandes realizadores disso, os amplos Estados de bem-estar social.

No tocante aos sistemas previdenciários, na década de 1990 ganharão corpo propostas de reforma em âmbito mais profundo ou sistêmico. Dräger (2003) sugere haver três principais grupos de argumentações pró-reforma: 1) os argumentos em torno da "bomba-relógio demográfica" - o aumento da longevidade e a diminuição do número de nascimentos tornaria o sistema financeiramente insustentável; 2) os argumentos em torno dos "custos do trabalho e competitividade" - graças às altas contribuições previdenciárias; e 3) os argumentos referentes à “justiça intergeracional” - os mais jovens, em nome da sustentabilidade de um número crescente de aposentados, deveriam aumentar suas contribuições.

Para Orszag e Stiglitz (1999), no coração das propostas reformadoras do sistema previdenciário, figurava um documento, elaborado pelo Banco Mundial em 1994, intitulado Averting Old Age Crisis: Policies to Protect the Old and Promote Growth ("Evitar a Crise do Envelhecimento: Políticas para proteger o Idoso e promover o Crescimento", em tradução livre). Nele, afirma-se que qualquer estratégia de provisão da seguridade aos idosos deveria ter como metas básicas ajudar tanto o idoso quanto a economia: "Programas para os idosos deveriam ser uma rede de segurança social e um instrumento para o crescimento [econômico]" (WORLD BANK, 1994, p. 233). O desenho do sistema previdenciário deveria equilibrar, portanto, as funções redistributiva, seguradora e de poupança, ao que se propõe um sistema "multipilar":

Este estudo recomenda separar as funções de poupança e redistributiva, colocando-as sob diferentes arranjos financeiros e gerenciais, em dois pilares distintos - um público e financiado com recursos fiscais, o outro privado e financiado por capitalização -, suplementados por um pilar voluntário para aqueles que queiram mais (WORLD BANK, 1994, p. 238). 
A proposta do Banco Mundial seria, então, a de um sistema com três pilares. O primeiro seria público-estatal, para reduzir ou aliviar a pobreza dos idosos nesta condição. O segundo, na forma de fundos de pensão administrados privadamente, mas com regulamentação pública, em geral com contribuição definida, complementaria o primeiro ao mesmo tempo em que permitiria a formação de estoques de capital para investimento etc. E o terceiro, voluntário, aos que quisessem uma renda suplementar, na forma de fundos de pensão privados, seguros, planos de poupança individuais etc.

A escolha dos três casos nacionais (Suécia, França, EUA) de reformas que serão vistos a seguir justifica-se pelo fato de que os três sistemas são em boa medida ilustrativos das modalidades sistêmicas supracitadas. Além disso, também seus respectivos movimentos laborais igualmente expressam diferentes modalidades de concepções político-ideológicas e sindicais.

\section{Suécia}

Até meados da década de 1990, o sistema previdenciário sueco, organizado segundo a lógica da repartição simples solidária (ou sistema PAYG, sigla para pay-as-you-go), combinava um benefício fixo básico - introduzido no início do século XX - e um benefício baseado em contribuições sobre o salário, instituído desde 1960 (KÖNBERG; PALMER; SUNDÉN, 2006). Incluídos no antigo sistema estavam também benefícios adicionais e auxílios habitacionais, estes para complementar os rendimentos dos que não têm o segundo benefício (ocupacional, a das contribuições sobre salários), ou que têm o mesmo em valor muito baixo (SCHERMAN, 1999).

De acordo com o antigo sistema, qualquer indivíduo que tivesse vivido pelo menos 40 anos na Suécia, ou que tivesse trabalhado por pelo menos 30 anos, teria assegurado um rendimento previdenciário básico e irredutível, calculado sobre um determinado valor-base. Tal pensão básica era indexada à variação do custo de vida. O cálculo do benefício complementar incluía a média dos 15 melhores anos (SCHERMAN, 1999).

Em relação ao financiamento do antigo sistema, originalmente se baseava em contribuições obrigatórias feitas pelo empregador, incidentes sobre a sua folha de salários, e por receitas gerais. $\mathrm{O}$ sistema pagava benefícios contributivos e não contributivos (os beneficiários por idade, invalidez, viuvez e filhos, todos eram partes do mesmo sistema) (KÖNBERG; PALMER; SUNDÉN, 2006).

A conjuntura política favorável à introdução de reformas no sistema sueco surgiu por ocasião de uma forte crise econômica e uma sensível elevação do desemprego no país no início dos anos 1990. Em apenas três anos - entre 1990 e 1993 - a taxa de desemprego aberto deu um salto, passando de 1,6\% para 8,2\% (HOLMLUND, 2003; LINDBOM, 2001)․․ Neste período, as contas públicas, antes superavitárias, conheceram um déficit correspondente a 12,3\% do PIB. A recessão minou as pré-condições do modelo de Welfare sueco, o pleno emprego e o crescimento econômico estável

1 A despeito dos temores de que esta alta taxa de desemprego se tornasse duradoura, já no final da década de 2000 a recuperação econômica fez baixar tal índice para algo em torno de 5\% (HOLMLUND, 2003). 


\section{(ANDERSON; MEYER, 2003).}

Já em meados dos anos 1980 o governo havia formado uma comissão para estudar o sistema previdenciário. Em 1990 o relatório foi concluído, e indicava problemas referentes à viabilidade financeira do sistema, sugerindo indexar os benefícios ao crescimento econômico, elevar a idade mínima para a aposentadoria e o número de anos exigidos para o direito integral ao benefício. Em princípio, o Partido Social-Democrata se opôs fortemente a reformas restritivas do sistema, mas foi derrotado nas eleições no início dos anos 1990, por uma coalizão de centro-direita (quatro partidos), que elegeu a reforma como prioritária ${ }^{2}$. Todavia, como a coalizão governamental de centro-direita tinha uma frágil base parlamentar, foi obrigada a buscar o apoio dos social-democratas para a causa da reforma. Deste modo, não teve como manter as pretensões originais e mais ousadas (em direção à privatização e capitalização) de empregadores e políticos conservadores (ANDERSON; MEYER, 2003). Foi formado um grupo parlamentar que incluía representantes dos cinco partidos e especialistas no tema, para tentar elaborar uma proposta comum de reforma. Um acordo foi alcançado no início de 1994, e a proposta foi aprovada no parlamento sueco em junho daquele ano, contando com $85 \%$ dos votos (KÖNBERG; PALMER; SUNDÉN, 2006).

A reforma sueca aprovada em 1994 contém cinco pontos: 1) os benefícios ocupacionais passaram a se basear em todo o tempo de trabalho, e não mais nos 15 melhores anos de 30; 2) as contribuições passaram a ser divididas igualmente entre empregados e empregadores; 3) novos índices entre benefício, variação salarial e crescimento econômico baseariam o ajuste do benefício; 4) direitos previdenciários poderiam ser divididos entre cônjuges, e "pontos de pensão" ${ }^{3}$ poderiam ser acumulados em atividades militares, criação de filhos e educação; finalmente, 5) do (novo) total de $18,5 \%$ da taxa de contribuição previdenciária, 2,5\% seriam alocados em uma reserva destinada a financiar fundos individuais de investimento. A partir de 61 anos, o benefício previdenciário poderia ser requerido (antes a idade mínima era 60 anos). A transição para o novo sistema levaria 20 anos (ANDERSON; MEYER, 2003) ${ }^{4}$.

O novo sistema previdenciário sueco resultou de um acordo firmado entre os socialdemocratas e os quatro principais partidos não socialistas, pelo qual todos assinariam a proposta em troca da satisfação de algumas demandas. Democratas cristãos e o Partido do Centro queriam dividir os direitos previdenciários entre os cônjuges; os social-democratas queriam manter o sistema

\footnotetext{
2 Tanto conservadores (segundo maior partido sueco) quanto liberais (terceiro) queriam contas individuais capitalizadas, enquanto o partido do Centro e os democratas cristãos não se opunham às mesmas, além de um benefício básico significativo (KÖNBERG; PALMER; SUNDÉN, 2006).

3 As modalidades de pontuação surgiram em alguns sistemas previdenciários (França, Noruega, Alemanha, Suécia, Eslováquia) e consistem em pontos que o trabalhador pode acumular, que se baseiam em fatores como rendimentos passados, extensão da cobertura, grau de escolarização etc. Quando da aposentadoria, a soma de pontos é multiplicada por um valor de referência fixado pelo governo, resultando no valor da aposentadoria (KALISCH; AMAN, 2001). Tal dispositivo não se confunde com o fator previdenciário brasileiro, pois este pune a aposentadoria precoce, enquanto aquele premia quem se aposenta mais tarde.

4 Além disso, a reforma sueca instituiu a contribuição "nocional": apesar de o sistema ser PAYG, trabalha-se com contas individuais virtuais, que servem de base para o cálculo do benefício previdenciário, sendo mais sensível a variações salariais. Também tende a conceder um valor maior a quem se aposentar mais tarde (DRÄGER, 2003).
} 
compulsório com altas taxas de reposição; liberais e conservadores queriam uma relação mais estreita entre contribuições e benefícios e os fundos de investimento (ANDERSON; MEYER, 2003).

Analisando as razões pelas quais foi possível uma reforma aprovada sem grandes atritos ou resistência por parte do sindicalismo, Anderson e Meyer (2003) destacam que a central sindical que reúne o conjunto de sindicatos de trabalhadores blue-collar, a LO, é estreitamente integrada à liderança do Partido Social-Democrata, e outras formas institucionalizadas de cooperação existem em níveis inferiores. Isso teria facilitado a comunicação entre o partido e os sindicatos no tocante a potenciais pontos de conflito, afinando o discurso entre as instâncias sindicais e partidárias.

A coalizão centro-direitista, ciente da força dos sindicatos, posicionou-se em geral de modo a não provocar a oposição sindical, o que implicava cessões diversas, a despeito de tentarem encaixar, ao menos parcialmente, mudanças no sistema. A LO não abriria mão do sistema público/ estatal previdenciário, mas teve que concordar com a divisão das contribuições entre empregados e empregadores.

A promessa de que o novo sistema elevaria o valor dos benefícios para a maioria dos trabalhadores com salários mais baixos também ajudou a atenuar a oposição inicial dos sindicatos à paridade entre empregado e empregador no financiamento do sistema, bem como a adoção dos fundos capitalizados. A LO defendia que os fundos fossem de adesão voluntária, enquanto a centrodireita queria que fossem obrigatórios. Chegou-se a uma espécie de meio termo: seria formado um fundo publicamente administrado para competir com os fundos privados e dada aos trabalhadores a opção de escolher por um ou outro (ANDERSON; MEYER, 2003).

Portanto, a despeito de uma crise econômica e do clima pró-reformas liberalizantes da centro-direita, o duo formado por LO e Partido Social-Democrata conseguiu reduzir o alcance das reformas propostas. Lindbom (2001) traz dados que mostram que a universalização da previdência seguiu crescendo e que as taxas de reposição mantiveram seu patamar pré-reforma, indicando a permanência do princípio de desmercadorização sugerido por Esping-Andersen (1990). Embora destaque, em outros setores (saúde, educação), tendências à liberalização, a generosidade do sistema sueco continuou similar à que havia no início dos anos 1980.

Com a crise financeira originada nos Estados Unidos em 2008, o sistema sueco, em princípio reformado para se ajustar "automaticamente" às flutuações econômicas de modo a manter o equilíbrio financeiro, foi severamente testado. A desvalorização geral dos ativos financeiros, mais a queda do crescimento econômico e do valor médio dos salários, afetariam os dois pilares do sistema - o de contribuição definida nocional e o complementar capitalizado - acabando por levar ao decréscimo do valor dos benefícios previdenciários. O sistema manteria o "equilíbrio financeiro", mas à custa da corrosão das aposentadorias. Em resposta, o governo, ou os partidos políticos que promoveram a reforma, foi obrigado a suavizar o processo de ajustamento dos benefícios previsto no período de transição. Na prática, o Estado assumiu o déficit resultante da suavização do "ajuste automático", impedindo que o crash do mercado financeiro afetasse o valor do benefício básico (SUNDÉN, 2009). Tal episódio seria indicativo de que, não obstante a chegada dos ventos liberalizantes na Escandinávia 
sueca, o sistema público continuaria resistindo em seus aspectos institucionais e sociopolíticos (resistências do meio sindical e dos políticos social-democratas).

\section{França}

O sistema previdenciário francês entraria no tipo "conservador-corporativista" de Esping-Andersen (1990), sendo principalmente financiado por contribuições de empregados e empregadores, as quais são gerenciadas por conselhos compostos por representantes dos mesmos. A aposentadoria é generosa, correspondendo, em média, a $70 \%$ do último salário (MANDIN; PALIER, 2005). O sistema é do tipo PAYG, embora em geral fragmentado por categorias profissionais, cada qual com seu próprio fundo previdenciário (PALIER, 2003).

A fragmentação ou descentralização do sistema previdenciário francês teria a ver com a evolução história do sindicalismo naquele país. Durante muito tempo o sindicalismo francês assumiu uma postura fortemente conflituosa em suas relações com o Estado, geralmente referido como um poder centralizado e autoritário representativo da burguesia. E por muito tempo desconfiaram de coisas como "seguro social" ou "pensão pública", por entenderem ser uma interferência do Estado no sentido de restringir a autonomia do trabalho. Após a II Guerra, retomou-se a discussão em torno da fundação de um sistema universal e centralizado. Os defensores de tal proposta não venceram a resistência dos grupos ocupacionais (fazendeiros, servidores, trabalhadores em ramos específicos da indústria, white collars etc.). Assim, além do régime général, esquemas separados (régimes spéciaux) foram estabelecidos para os grupos ocupacionais que já eram cobertos por esquemas similares antes de 1945 (BÉLAND, 2001).

A arquitetura do sistema varia em função do setor de atividade (público ou privado). No setor privado, os trabalhadores são cobertos por um esquema com dois pilares. O primeiro (régime général), geral e organizado por lei, abrange todos os trabalhadores, embora exista principalmente para proteger os trabalhadores empregados em modalidades atípicas ou carreiras fragmentadas (incluindo-se aí os intervalos para criação de filhos). E o segundo (régimes spéciaux), também compulsório, refere-se às categorias profissionais, sendo regulado por acordos coletivos. No setor público, um único pilar garante $75 \%$ do último salário. Há ainda um sistema assistencial para o idoso que não contribuiu, uma renda mínima destinada aos muito pobres (MANDIN; PALIER, 2005).

A despeito de ser compulsória, a maior parte do volume de recursos do sistema - os fundos previdenciários relativos a categorias profissionais - não é administrada pelo Estado, e sim pelos referidos conselhos bipartites. Pensões suplementares, de tipo fully funded (ou seja, que seus ativos, capitalizados, devem ser iguais ou superiores ao montante de passivos), podem ser adicionadas à pensão compulsória, e são oferecidas em determinados setores e empresas, contando com a adesão voluntária do trabalhador. Neste sentido, o debate sobre a estrutura previdenciária francesa não girou necessariamente em torno da oposição entre sistema público 
e sistema privado, mas entre sistema compulsório e opcional, bem como entre sistemas PAYG e capitalizado (PALIER, 2003).

O sistema previdenciário francês seguiu se expandindo durante as décadas de 1970 e até o início dos anos 1980 - a "idade de ouro" da previdência francesa (MANDIN; PALIER, 2005) -, com a elevação do piso do valor básico e a diminuição da idade mínima para a aposentadoria, sendo obtida em reforma realizada pelo governo socialista em 1982. A partir daí, contudo, o movimento sindical francês começou a se enfraquecer, enquanto se fortalecia a posição dos que queriam reformar a previdência de modo a diminuir ou restringir seus benefícios (BÉLAND, 2001).

Em 1993, com a vitória da direita nas eleições gerais, o governo Balladur lançou uma proposta de reforma. Sabendo que enfrentaria forte resistência se tentasse fazer uma reforma contrariamente aos sindicatos, Balladur ofereceu uma troca. Ele propôs separar os benefícios previdenciários contributivos dos não contributivos, o que atenderia uma antiga reivindicação dos meios sindicais - que não queriam financiar, mediante contribuições sobre o salário do trabalhador, os benefícios básicos de combate à pobreza (destinados aos indivíduos sem renda suficiente para constituírem seus próprios fundos previdenciários). Os sindicatos aceitaram a oferta e em troca permitiram a elevação do tempo de contribuição e a diminuição potencial do valor básico da aposentadoria (aumentando o número de melhores anos a serem considerados na média calculada para o valor) (JEGER; LELIEVRE, 2005).

Em 1995, sob o governo de Juppé, tentou-se nova reforma, agora sobre o principal componente do sistema, os regimes especiais. Diferentemente de Balladur, porém, o governo optou por tentar aprovar a reforma ignorando os sindicatos. Em resposta, os sindicatos promoveram a maior onda de greves desde 1968, literalmente parando o país - paralisou-se o sistema de transporte, enquanto dois milhões de trabalhadores cruzavam os braços, contando com amplo apoio popular. O governo foi obrigado a retirar a proposta. A partir de então os dirigentes governamentais ficaram mais cautelosos em relação ao tema da reforma da previdência. Em fins dos anos 1990 uma nova organização empresarial, a Movement des Enterprises de France (MEDEF), assumiu o papel de levar adiante propostas de reforma, que buscavam disseminar a ideia de formar fundos de pensão através de reformas dos fundos dos regimes especiais. $\mathrm{E}$ também foram fortemente repudiados pelos sindicatos (BÉLAND, 2001).

Com a vitória de Chirac nas eleições presidenciais de 2002, este designou Jean-Pierre Raffarin como primeiro-ministro, o qual tinha a reforma previdenciária em sua agenda. A proposta do governo era aproximar as condições reinantes no setor público, mais generosas, para as existentes no setor privado. Propunham-se medidas como a elevação do tempo de contribuição, incentivos para quem se aposentasse além da idade legal, sanções em caso contrário etc. E novamente as centrais sindicais se puseram em marcha, mais uma vez levando cerca de dois milhões de trabalhadores à paralisação (JEGER; LELIEVRE, 2005). Contudo, nesta ocasião o movimento sindical se dividiu entre centrais que aceitaram barganhar e centrais 
que mantiveram o veto incondicional à reforma. Assim, no setor público acabou-se por elevar um pouco mais o tempo de contribuição, além de haver mecanismos de redução do valor da aposentadoria em caso de menor tempo de contribuição.

Embora o governo tenha anunciado a criação de novos fundos voluntários regidos pelo princípio da capitalização, as reformas feitas não tocaram a natureza PAYG do sistema francês. Mas o meio sindical, ou pelo menos algumas de suas principais centrais, começou a considerar a possibilidade de concordar com o desenvolvimento de fundos de pensão, desde que como forma complementar do sistema PAYG e desde que participem ativamente da gestão dos mesmos. Ganharam força também argumentações no sentido de se utilizar tais novos fundos de pensão como instrumento de vigor econômico (investimentos etc.) e como forma de compensar a perda relativa de poder dos sindicatos em seu campo habitual, relativo à negociação coletiva etc. $\mathrm{O}$ resultado seria um sistema misto (MANDIN; PALIER, 2005) ${ }^{5}$.

\section{Estados Unidos}

O moderno sistema de previdência pública norte-americana nasceu na administração Roosevelt. Em 1935, o Social Security Act incluía dois programas para os idosos: o Seguro para o Idoso (Old Age Insurance) e à Assistência para o Idoso (Old Age Assistance). No início, o primeiro programa pagava poucos rendimentos aos trabalhadores, enquanto o benefício assistencial era maior e mais popular. Não obstante, rapidamente acelerou-se a expansão do sistema contributivo, e foram adicionados benefícios para dependentes de aposentados e para a viuvez. Em breve a vasta maioria dos trabalhadores, incluídos os autônomos, estava coberta pelo sistema. Em 1972 os benefícios contributivos foram indexados à inflação (WEAVER, 2005). Este sistema permanece até hoje.

$\mathrm{O}$ chamado de Seguro à Velhice e à Sobrevivência (Old Age and Survivors Insurance, OASI), ou popularmente de Seguro Social (Social Security), organizado segundo o esquema PAYG, depende inteiramente de contribuições sobre os salários, divididos igualmente entre trabalhadores e empregadores, de 12,4\% (WEAVER, 2005). Contudo, o valor dos benefícios é de tal modo que trabalhadores com salários menores recebem um retorno sobre suas contribuições mais elevado do que os trabalhadores com salários/contribuições mais elevados (SCHWARZE; FRICK, 2000).

Dadas estas características da dimensão público-estatal do sistema norte-americano - baseado nos rendimentos do trabalho, contributivo, mas com taxas de reposição baixas relativamente às europeias -, Weaver (2005) o caracteriza como "bismarckiano leve". Não

\footnotetext{
5 As reformas ocorridas em 2010, no governo Sarkozy, acabaram por efetivar a lógica mista do sistema francês. A despeito da resistência sindical, a idade mínima foi elevada e os fundos de pensão entraram com mais força enquanto benefícios complementares. Os valores médios dos benefícios caíram. Para maiores detalhes sobre o atual estado previdenciário francês, consultar a coletânea de dados contida em http://drees.solidarites-sante.gouv. fr/IMG/pdf/dd9 en.pdf (Acesso em 20 fev. 2018).
} 
por acaso, o sistema público norte-americano incentiva fortemente o recurso a esquemas privados de previdência, de forma a complementar a renda da aposentadoria (SCHWARZE; FRICK, 2000). Nos Estados Unidos há um leque complexo de incentivos fiscais para encorajar e estimular a criação de planos de previdência privada, tanto no âmbito das empresas, quanto planos individuais (HACKER, 2004). Os fundos de pensão patrocinados por empresas são desigualmente distribuídos, porém, sendo mais comuns entre funcionários públicos e trabalhadores sindicalizados do que no restante dos trabalhadores (WEAVER, 2005).

Uma lei federal de 1974 (Employee Retirement Income Security Act, ou ERISA) estabelece padrões mínimos para a maioria dos planos de previdência voluntários, além de prever proteções legais diversas aos participantes e beneficiados pelos planos. Criou-se também uma agência federal de monitoramento e regulação dos diversos planos (Pension Benefit Guaranty Corporation - PBGC). ${ }^{6}$ Os fundos de pensão podem ser na forma de contribuição definida ou de benefício definido - os últimos são mais comuns entre servidores públicos -, e podem ser patrocinados por uma empresa ou por diversas (multiemployer plans), sendo os últimos mais comuns entre trabalhadores sindicalizados (e o sindicato negocia com as diversas empresas). Em março de 2010, 50\% dos trabalhadores do setor privado norte-americano participavam de algum fundo de pensão (acessíveis, contudo, a 65\% dos trabalhadores), enquanto no setor público, $85 \%$ dos servidores eram participantes (com acesso a 90\% deles). No setor privado, são significativas as diferenças existentes entre trabalhadores sindicalizados (82\% participavam de algum plano de pensão) e não sindicalizados (46\%), bem como entre trabalhadores fulltime (59\%) e part-time (21\%), e entre os que trabalham em estabelecimentos com mais de 500 funcionários (75\% com planos de pensão) e com até 99 empregados (35\%) ${ }^{7}$. A realidade dos planos de aposentadoria privados existentes nos Estados Unidos é muito complexa para ser tratada em profundidade aqui ${ }^{8}$.

Em relação ao sindicalismo norte-americano, uma das questões em que os analistas se debruçam é saber por que há diferenças aparentemente tão significativas entre este e o movimento sindical europeu, sendo que os EUA pertencem ao grupo de nações capitalistas mais ricas e desenvolvidas. Para Alesina, Glaeser e Sacerdote (2001), uma possível razão estaria no processo histórico de formação da classe trabalhadora norte-americana. Tendo sido composta por ondas de movimentos migratórios ao longo de um amplo período histórico, a classe trabalhadora estadunidense seria marcada por agudas diferenciações de natureza religiosa (católicos, protestantes etc.) e étnico-cultural (diversas nacionalidades europeias, asiáticas e latino-americanas, além da presença africana quando do passado escravista do país). Tais fatores teriam bloqueado a constituição de uma "consciência de classe" ao estilo europeu.

6 United States Department of Labor. http://www.dol.gov/dol/topic/health-plans/erisa.htm. Acesso em 16 out. 2010. 7 Bureau of Labor Statistics, U.S. Department of Labor, http://www.bls.gov/ncs/ebs/sp/ebnr0016.pdf. Acesso em 19 ago. 2010).

8 Os principais são os seguintes: 401(k), Safe Harbor 401(k), Automatic Enrollment 401(k), Simple IRA, SEP, ESOP, Profit-sharing Plan. Para maiores detalhes, ver Soria (2011). 
Com efeito, os movimentos de trabalhadores norte-americanos no século XIX, que poderiam ter sido precursores de agremiações sindicais e partidárias de tipo socialista, reproduziam valores e referências ideológicas próprias da “democracia jakcsoniana”, que enfatizava bandeiras como a da igualdade de oportunidades (embora, originalmente, com forte viés racista ou supremacista branco) e a de um orgulho "nativista", que, contraditoriamente, se colocava como crítico tanto dos "estrangeiros" que chegavam ao país vindos do Velho Mundo, quanto dos povos indígenas pré-colombianos (ALESINA; GLAESER; SACERDOTE, 2001).

Quando da Grande Depressão, momento em que ideais socialistas ou trabalhistas poderiam ter conhecido uma relativa ascensão entre os trabalhadores, o então Governo Roosevelt e o Partido Democrata buscaram, com sucesso, envolver ou incorporar lideranças operárias e assalariadas que, de outro modo, poderiam ter aderido ao ideário socialista ou social-democrata. Ao mesmo tempo, os socialistas estadunidenses aparentemente não compreenderam, e tampouco acomodaram ou assimilaram ao seu ideário político-ideológico e programático, traços bastante fortes da cultura americana, como o antiestatismo e o individualismo (LIPSET; MARKS, 2001).

Historicamente, o modo como a questão previdenciária foi debatida pelo sindicalismo norte-americano parece ter tido significativa influência sobre a configuração do sistema previdenciário estadunidense. No início do século XX, o meio sindical norte-americano foi extremamente relutante, quando não simplesmente refratário, a uma lógica de aposentadorias público-estatais. O primeiro presidente da American Federation of Labor (AFL), Samuel Gompers ${ }^{9}$, considerava pensões públicas e seguros sociais estatais em geral como ameaças à autonomia do trabalho organizado (FORBATH, 1991). Esta atitude antiestatista, de acordo com alguns estudiosos, teria emergido como uma reação ao elevado grau de hostilidade manifestado pela Suprema Corte contra o sindicalismo. Somente durante o New Deal a AFL passou a apoiar a existência de pensões públicas (HATTAM, 1993).

Quando do Social Security Act (SSA), de 1935, que inaugurou o sistema público de seguro e benefícios à condição de velhice, os sindicatos não demonstraram muito interesse, além do que, o sistema foi concebido e implementado para ser administrado integralmente pela burocracia estatal. Quando muito, os sindicatos acabaram na condição de "colaboradores políticos" do SSA. Ao mesmo tempo, o grosso da energia do sindicalismo neste front foi canalizado para a expansão dos sistemas privados de pensão e aposentadoria, os quais, a partir dos anos 50, passaram gradualmente a ser ponto de pauta nos processos de barganha coletiva. Neste sentido, os fundos de pensão são considerados, pelo meio sindical norte-americano em geral, como uma conquista do sindicalismo estadunidense (BÉLAND, 2001).

Enquanto isso, o Social Security seguiu se expandindo, alcançando o auge no início dos anos 1970, com a elevação dos benefícios bem acima da inflação (entre 1969 e 1972), e indexação à inflação a partir de 1972. A classe média também se tornou ator cada vez mais interessado

9 Fundador e presidente da AFL por um extenso período, de 1886 a 1894 e de 1895 até a sua morte, em 1924 (http:// en.wikipedia.org/wiki/Samuel_Gompers. (Acesso em 20 ago. 2010). 
neste direito, unindo-se aos sindicatos, que também pressionavam neste sentido (sem deixar de lado, como mencionado, a atenção aos planos privados de previdência). A partir da segunda metade da década de 1970, contudo, o enfraquecimento do sindicalismo e as crises econômicas fizeram diminuir o impulso em favor da expansão dos esquemas estatais/públicos de bem-estar em geral, e os relativos à previdência em particular (BÉLAND, 2001).

Com Reagan, a partir da década de 1980, tem início o movimento de tentativa de aplicação de cortes nos benefícios. Um primeiro plano de cortes, previsto para o orçamento de 1982, foi fortemente rechaçado pelos sindicatos e pelos democratas, e o governo recuou, mudando de estratégia: lançou uma comissão sobre reforma do sistema. Esta se limitou a propor a elevação da idade mínima (65 para 67 anos), bem como uma unificação das regras para os servidores públicos. Desta vez, os sindicatos não conseguiram obstar a proposta, que contava com a participação de democratas na comissão (BÉLAND, 2001).

Nos dois governos Clinton também houve ensaios de alteração no Social Security. No primeiro governo, uma comissão bipartidária foi feita para estudar o sistema e fazer recomendações, mas não produziu nenhum consenso. E no segundo governo houve uma discussão em torno do ajuste da fórmula de indexação dos benefícios à inflação, de modo a reduzir os reajustes. Mas também não houve continuidade. Em dezembro de 2014, o governo Obama aprovou o Multiemployer Pension Reform Act, que autorizava a redução temporária do valor dos benefícios pagos em fundos de múltiplos empregadores em risco de insolvência, desde que submetido o pedido ao Pension Benefit Guaranty Corporation (PBGC) ${ }^{10}$, que seguiria segurando os fundos.

Dadas as transformações ocorridas no mundo do trabalho estadunidense, como as diversas modalidades de trabalho e de remuneração (jornada e salários flexíveis, intensificação do ritmo de trabalho etc.), e os correspondentes riscos sociais que estas acarretaram, o sistema previdenciário não foi atualizado de modo a cobrir também estes novos riscos, o que equivaleria, na prática, a uma corrosão do sistema. Para Hacker (2004, p. 256), estaria em curso uma "privatização dos riscos (sociais) sem a privatização do welfare state".

Aparentemente, nos Estados Unidos o sindicalismo nunca se identificou profundamente com o sistema público previdenciário e nunca teve participação formal no gerenciamento do sistema, de modo que sua posição institucional e ideológica neste campo sempre foi frágil, não tendo um "poder de veto" (formal ou informal) similar ao observado nos meios sindicais europeus (BÉLAND, 2001).

\section{Lições nacionais: sindicalismo e reforma previdenciária no Brasil}

Uma vez que o objetivo principal deste trabalho foi o de fornecer um (ainda que breve) panorama das experiências internacionais de reformas previdenciárias e dos papeis assumidos

10 PBGC é a agência federal norte-americana responsável pela regulação, monitoramento e fiscalização da parte do sistema previdenciário em que atuam os fundos de pensão. Foi criado por ocasião da ERISA, em 1972. 
pelos respectivos movimentos sindicais, e dados os limites de espaço existentes, não seria possível proceder a uma profunda investigação desta questão na especificidade brasileira. Não obstante, fazem-se necessárias algumas considerações neste sentido. Partamos, pois, do ciclo de reformas ocorrido no país entre 1998 e $2012^{11}$.

Por um lado, é possível considerar as reformas do sistema previdenciário nacional sob os Governos Cardoso (Emenda Constitucional 20/1998 e Lei 9.876/1999, esta sendo a da adoção do "fator previdenciário"), Lula (EC 41/2003 e EC 47/2005) e Rousseff (Lei 12.618/2012) como constitutivas de um mesmo movimento geral de reforma, considerando-se objetivos como a diminuição dos custos do sistema e o afastamento relativo do ideal da desmercadorização dos benefícios previdenciários (SORIA, 2014). Por outro lado, ao se considerar também as orientações político-ideológicas distintas dos governos que efetivaram as reformas, os objetivos próprios de cada reforma e os posicionamentos assumidos pelo movimento sindical em cada um dos episódios, um cenário mais complexo surge à vista.

Assim, o Governo FHC buscou uma reforma ampla (inspirada na perspectiva do Banco Mundial destacada neste artigo), que afetasse tanto a previdência público-estatal (RPPS) quanto a privada (RGPS/INSS) ${ }^{12}$, contando com decidida oposição do movimento sindical e políticopartidário correspondente (composto tanto pela Central Única dos Trabalhadores, quanto pelo Partido dos Trabalhadores). Cardoso logrou sucesso no tocante à previdência do setor privado, com a introdução do fator previdenciário no cálculo dos benefícios, além de elevar a idade mínima para servidores, e também lançando as bases para a expansão do pilar previdenciário complementar (fundos de pensão), embora não tenha conseguido avançar, neste sentido, sobre o funcionalismo público - graças, em boa medida, à oposição do sindicalismo supracitada.

Já as reformas dos Governos Lula e Rousseff poderiam ser consideradas em conjunto, dado que foram governos do PT que contaram com apoio formal do sindicalismo cutista. Como então explicá-las, dadas as forças políticas (e sindicais) que as tiraram do papel? Primeiramente, não seria de grande auxílio, para tanto, lembrar que o conteúdo das reformas Lula e Rousseff representavam perdas menos efetivas para os trabalhadores se comparadas com o que o Governo FHC realizou e buscava realizar.

Isso em parte é verdade ${ }^{13}$, mas não muda o fato de que a desmercadorização parcial do sistema (via expansão dos fundos de pensão pelo serviço público federal, com o fim da aposentadoria integral e a extensão do teto de benefícios do INSS para os servidores), que só não foi totalmente lograda sob FHC por oposição petista e cutista, foi finalmente efetivada pelos governos petistas.

11 Para um levantamento mais detalhado da constituição histórica da previdência brasileira, ver Soria (2011).

12 Sumariamente, a previdência social brasileira pode ser hoje descrita como sendo composta por três regimes: o Regime Geral de Previdência Social (RGPS), gerenciado pelo Instituto Nacional do Seguro Social (INSS); os Regimes Próprios de Previdência Social (RPPS), de servidores públicos civis e militares; e o regime de previdência complementar, com fundos de pensão existentes desde os anos 1970 no país, consagrado na Reforma FHC e estendido na Reforma Rousseff para o serviço público federal, na forma da Fundação de Previdência Complementar do Serviço Público Federal (FUNPRESP) (SORIA, 2014).

13 Ver Soria (2011) para um comparativo entre as reformas FHC e Lula. 
A resposta deve estar em algum lugar na seguinte ordem de considerações. Primeiramente, a força hegemônica no sindicalismo da CUT situa-se nos fortes sindicatos de setores produtivos de destaque na iniciativa privada, como o bancário e o metalúrgico, assim como em empresas públicas, como é o caso do setor petroleiro e também dos grandes bancos públicos nacionais. Nestes setores, cujos sindicatos compõem o núcleo dirigente da CUT, o convívio dos trabalhadores com fundos de pensão existia desde os anos 1970. Para Grün (2003), o interesse dos sindicatos pelos fundos de pensão era justificado pela convicção de que a legitimidade de seu mandato sindical como representantes dos trabalhadores deveria ser estendida para a esfera previdenciária. Para Jardim (2008), desde os anos 1990, aqueles sindicatos foram se interessando pelos temas da criação e gestão de fundos previdenciários, inserindo-os na pauta sindical.

Assim, a vitória de Lula e do PT, cujas elites partidárias coincidiam em grande medida com as elites sindicais cutistas, surgiu como oportunidade dourada para que o processo de expansão do pilar previdenciário na forma de fundos de pensão pudesse ocorrer sob seu controle (SORIA, 2011). Aparentemente, neste aspecto pelo menos, os movimentos sindical e políticopartidário representados por CUT e PT guardariam menos semelhança com os movimentos sindicais e partidários socialistas ou social-democratas europeus, e mais com seus congêneres norte-americanos (SORIA, 2014).

\section{Conclusões}

Os casos vistos aqui, assim como as posturas do sindicalismo relativas àqueles e as posturas que tinham ou assumiram quando dos processos de reforma ocorridos, permitem as seguintes considerações: em primeiro lugar, a importância do sindicalismo é central, tanto na fase histórica de construção dos sistemas previdenciários, quanto nos períodos em que aquela construção primeira é submetida à crítica e às tentativas de reformulação.

Segue em marcha o discurso e/ou as práticas liberalizantes como fatores corrosivos da estrutura do sistema público-estatal de seguridade - corrosão esta cujos efeitos serão mais sensíveis quanto menos extensas forem tais estruturas, e quanto menor for a capacidade de manutenção ou defesa das mesmas. A crítica contínua de tudo que lembre a seguridade público-estatal postula a desmercadorização de aspectos da vida social então pertencentes ou incorporados à esfera da cidadania.

O movimento sindical, por sua vez, não é imune ao ambiente econômico, políticoinstitucional e ideológico que o circunda socialmente. Suas respostas aos desafios postos refletem concepções de mundo, não sendo apenas respostas “objetivas” em uma lógica de pragmatismo ou realismo. Neste sentido, movimentos de recuo dos sindicatos podem guardar explicações distintas.

A questão da polarização entre interesses correspondentes a segmentos jovens e maduros das classes assalariadas é importante, mas devem ser considerados fatores de natureza mais 
geral, como a própria conjuntura histórica, de luta pela manutenção de traços "antivalor" em um cenário de avalanche de concepções individualistas, competitivas e menos afeitas a valores comunitários e solidários, e que expressa a utopia liberal de mercantilização plena da vida social.

\section{Referências}

ALESINA, A.; GLAESER, E.; SACERDOTE, B. Why doesn't the US have a European-Style Welfare State? Harvard Institute of Economic Research, Cambridge, Discussion Paper, n. 1933, p. 187-278, nov., 2001.

ANDERSON, K. M.; MEYER, T. Social Democracy, Unions, and Pension Politics in Germany and Sweden. Journal of Public Policy, Cambridge, v. 23, n.1, p. 23-54, jan. 2003.

ANTUNES, R. Adeus ao Trabalho? Ensaio sobre as Metamorfoses e a Centralidade do Mundo do Trabalho. São Paulo: Cortez, 1995.

BIHR, A. Da grande noite à alternativa: o movimento operário europeu em crise. São Paulo: Boitempo, 1999.

BÉLAND, D. Does Labor Matter? Institutions, Labor Unions and Pension Reform in France and United States. Journal of Public Policy, Cambridge, v. 21, n. 2, p. 153-172, mai./ago. 2001.

BRUGIAVINI, A.; EBBINGHAUS, B.; FREEMAN, R.; GARIBALDI, P.; SCHLUDI, M.; VERDIER, T. Part II: What Do Unions Do to the Welfare States? In: BOERI, T.; BRUGIAVINI, A.; CALMFORS, L. (Eds.). The Role of Unions in the Twenty-First Century: A Report to the Fondazione Rodolfo Debenedetti. Oxford: Oxford University Press, 2001. p. 157-277.

DONADO, A.; WÄLDE, K. How trade unions increase welfare. The Economic Journal, London, v. 122, n. 563, p. 990-1009, set., 2012.

DRÄGER, K. Pension Reform in the European Union. In: CONFERENCE ON THE PRIVATIZATION OF PUBLIC PENSION SYSTEMS: FORCES, EXPERIENCES, PROSPECTS, Vienna. Paper presented to the Conference on the Privatization of Public Pension Systems: Forces, Experiences, Prospects, Vienna, jun. 2003. p. 19-21.

ESPING-ANDERSEN, G. The Three Worlds of Welfare Capitalism. Princeton: Princeton University Press, 1990. FORBATH, W.E. E. Law and the Shaping of the American Labor Movement. Cambridge: Harvard University Press, 1991.

GOUGH, I. The Political Economy of the Welfare State. London: Macmillan, 1979.

GOUREVITCH, P. Politics in Hard Times: Comparative Responses to International Economic Crisis. Ithaca: Cornell University Press, 1986.

GRÜN, R. Atores e ações na construção da "governança corporativa" brasileira. Revista Brasileira de Ciências Sociais, São Paulo, v. 18, n. 52, p. 1-24, jun. 2003.

HACKER, J. S. Privatizing Risk without Privatizing the Welfare State: The Hidden Politics of Social Policy Retrenchment in the Unites States. American Political Science Review, Washington, v. 98, n. 2, p. 243-260, mai. 2004. HATTAM, V. C. Labor Visions and State Power: The Origins of Business Unionism in the United States. Princeton: Princeton University Press, 1993.

HOLMLUND, B. The Rise and Fall of Swedish Unemployment. CESIFO Working Paper Series, Munich, n. 918, p. 1-58, 2003.

HYMAN, R. Trade unions and the politics of the European social model. LSE Research Online, London, v. 26, n.1, p. 9-40, fev. 2005. Disponível em: https://journals.sagepub.com/doi/10.1177/0143831X05049401. Acesso em 25 jul. 2010.

JARDIM, M. A. C. Fundos de pensão no Brasil: novo ethos sindical? Colóquio Saber e Poder. Focus: Unicamp, 2008. 
JEGER, F.; LELIEVRE, M. The French pension system and 2003 reform. The Japanese Journal of Social Security Policy, Tóquio, v. 4, n. 2, p. 76-84, dez. 2005.

KALISCH, D.W.; AMAN, T. Retirement Income Systems: the Reform Process Across OECD COUNTRIES. In: DISNEY, R.; JOHNSON, P. (Eds.) Pension Systems and Retirement Income Across OECD Countries. Cheltenhan (United Kingdom): Edgar Elgar Publishing limited, 2001. p. 1-83.

KÖNBERG, B.; PALMER, E.; SUNDÉN, A. The NDC Reform in Sweden: the 1994 Legislation to the Present. In: HOLZMANN, R.; PALMER, E. (Eds.) Pension Reform: Issues and Prospects for Non-financial Defined Contribution (NDC) Schemes. Washington: The World Bank, 2006. p. 449-466.

LINDBOM, A. Dismantling the Social Democratic Welfare Model? Has the Swedish Welfare State Lost Its Defining Characteristics? Scandinavian Political Studies, v. 24, n. 3, p. 171-193, 2001.

LIPSET, S.; MARKS, G. It didn't happen here: Why socialism failed in the United States. New York: W.W. Norton\&Co., 2001.

MANDIN, C.; PALIER, B. The politics of pension reform in France: the end of exceptionalism? In: BONOLI, G.; SHINKAWA, T. (Eds.) Ageing and Pension Reform Around the World: Evidence from eleven countries. Cheltenhan (United Kingdom): Edgar Elgar Publishing limited, Chapter 4, 2005. p. 74-93.

MARES, I. Strategic Alliances and Social Policy Reform: Unemployment Insurance in Comparative Perspective. Politics \& Society, v. 28, n. 2, p. 223-244, 2000.

MARSHALL, T. H. Cidadania, Classe Social e Status. Rio de Janeiro: Zahar, 1967.

NATALI, D.; RHODES, M. Welfare Regimes and Pension Reform Agendas. In: CONFERENCE ON PENSION REFORM IN EUROPE: SHARED PROBLEMS, SHARING SOLUTIONS, London. Proceedings of the Conference on Pension Reform in Europe: shared problems, sharing solutions. London: London School of Economics and Political Science, 2003. p. 1-12

O’CONNOR, J. A Crise Fiscal do Estado. Rio de Janeiro: Paz e Terra, 1977.

ORSZAG, P. R.; STIGLITZ, J. E. Rethinking Pension Reform: Ten Myths About Social Security Systems. In: WORLD BANK CONFERENCE, Washington. HOLZMANN, R; STIGLITZ, J. E. (Eds.). New Ideas About Old Age Security. Washington: World Bank, 1999. p. 1-46.

PALIER, B. Facing the Pension Crisis in France. In: CLARK, G. L.; WHITESIDE, N. (Eds.). Pension Security in the 21st Century. Oxford: Oxford University Press, 2003.

PRZEWORSKI, A. Capitalism and Social Democracy. Cambridge: Cambridge University Press, 1985.

SCHERMAN, K. G. The Swedish pension reform: Framework and Issues. In: Issues in Social Protection. Geneva: International Labour Organization, 1999. p. 1-50.

SCHMITTER, P. Still the Century of Corporatism? In: PIKE, F., STRITCH, T. The New Corporatism. London: University of Notre Dame Press, 1974. p. 85-131.

SCHWARZE, J.; FRICK, J. R. Old Age Pension systems and the income distribution among the elderly - German and United States Compared. In: HAUSER, R; BECKER, I. (Eds.). The personal distribution of income in an international perspective. Heidelberg: Springer, 2000. p. 225-243.

SORIA, S.S. Intersecção de classes: fundos de pensão e sindicalismo no Brasil. 2011. 426 f. Tese (Doutorado em Sociologia) - Instituto de Filosofia e Ciências Humanas, Programa de Doutorado em Sociologia, Unicamp, Campinas. Sindicalismo e fundos de pensão no Governo Lula: da segurança do Estado à aposta no mercado. In: ANTUNES, R. (Org.) Riqueza e Miséria do Trabalho no Brasil III. São Paulo, Boitempo, 2014, p. 349-369.

STREECK, W.; HASSEL, A. Trade unions as political actors. In: ADDISON, J.; SCHNABEL, C. (Eds.). International Handbook of Trade Unions. Cheltenhan (UK): Edward Elgar Pub, 2003. p. 1-52 
SUNDÉN, A. The Swedish Pension System and the Economic Crisis. Center for Retirement Research at Boston College. n. 9-25, p. 1-5, dez. 2009.

WEAVER, R. K. Public pension reform in the United States. In: BONOLI, G.; SHINKAWA, T. (Eds.) Ageing and Pension Reform Around the World: Evidence from eleven countries. Cheltenhan (United Kingdom): Edgar Elgar Publishing limited, 2005.

WORLD BANK, Averting the Old Age Crisis: Policies to Protect the Old and Promote Growth. Oxford: Oxford University Press, 1994.

Recebido em: 31/07/2017 Aceito em: 21/08/2018 